Annika Wennerström ${ }^{1}$, Anne Pietinalho ${ }^{2}$, Jagoda Lasota ${ }^{1}$, Krista Salli ${ }^{1}$, Ida Surakka ${ }^{3}$, Mikko Seppänen ${ }^{4}$, Olof Selroos ${ }^{5}$ and Marja-Liisa Lokki ${ }^{1}$

${ }^{1}$ Transplantation Laboratory, Haartman Institute, University of Helsinki, Helsinki, ${ }^{2}$ Raasepori Health Care Centre, Raasepori, ${ }^{3}$ FIMM, Institute for Molecular Medicine Finland, Biomedicum, University of Helsinki, Helsinki, and ${ }^{4}$ Immunodeficiency Unit, Division of Infectious Diseases, Dept of Medicine, Helsinki University Central Hospital, Helsinki, Finland. ${ }^{5}$ Semeco AB, Vejbystrand, Sweden.

Correspondence: A. Wennerström, Transplantation Laboratory, Haartman Institute, P.O. Box 21, FI-00014 University of Helsinki, Helsinki, Finland. E-mail: annika.wennerstrom@helsinki.fi

Received: Feb 262013 | Accepted after revision: Feb 282013

Support statement: This study was supported by the Nummela Foundation for Medical Research, Hengityssairauksien tutkimussäätiö, the Helsinki Biomedical Graduate Programme (HBGP), and the League of European Research Universities (LERU).

Conflict of Interest: Disclosures can be found alongside the online version of this article at www.erj.ersjournals.com

Acknowledgements: The authors thank the patients for their participation and the clinicians for their time and efforts to make this study possible. We also thank L. Saraste (Transplantation Laboratory, Haartman Institute, University of Helsinki, Helsinki, Finland) for reviewing the English language and M. Veini, L. Snellman, K. Roine, E. Lahtela (all at the Transplantation Laboratory, Haartman Institute, University of Helsinki, Helsinki, Finland) and M. Kaunisto (FIMM, Institute for Molecular Medicine Finland, Biomedicum, University of Helsinki, Helsinki) for their contribution to gene analyses.

\title{
References
}

Iannuzzi MC, Rybicki BA, Teirstein AS. Sarcoidosis. N Engl J Med 2007; 357: 2153-2165.

2 Sato H, Woodhead FA, Ahmad T, et al. Sarcoidosis HLA class II genotyping distinguishes differences of clinical phenotype across ethnic groups. Hum Mol Genet 2010; 19: 4100-4111.

3 Milman N, Selroos O. Pulmonary sarcoidosis in the Nordic countries 1950-1982. Epidemiology and clinical picture. Sarcoidosis 1990; 7: 50-57.

4 Richeldi L, Sorrentino R, Saltini C. HLA-DPB1 glutamate 69: a genetic marker of beryllium disease. Science 1993; 262: 242-244.

5 Valentonyte R, Hampe J, Huse K, et al. Sarcoidosis is associated with a truncating splice site mutation in BTNL2. Nat Genet 2005; 37: 357-364.

6 Sato H, Spagnolo P, Silveira L, et al. BTNL2 allele associations with chronic beryllium disease in HLADPB1*Glu69-negative individuals. Tissue Antigens 2007; 70: 480-486.

7 Maliarik MJ, Chen KM, Major ML, et al. Analysis of HLA-DPB1 polymorphisms in African-Americans with sarcoidosis. Am J Respir Crit Care Med 1998; 158: 111-114.

8 Wennerström A, Pietinalho A, Vauhkonen $\mathrm{H}$, et al. HLA-DRB1 allele frequencies and C4 copy number variation in Finnish sarcoidosis patients and associations with disease prognosis. Hum Immunol 2012; 73: 93-100.

9 Darlington P, Tallstedt L, Padyukov L, et al. HLA-DRB1* alleles and symptoms associated with Heerfordt's syndrome in sarcoidosis. Eur Respir J 2011; 38: 1151-1157.

10 Rossman MD, Thompson B, Frederick M, et al. HLA-DRB1*1101: a significant risk factor for sarcoidosis in blacks and whites. Am J Hum Genet 2003; 73: 720-735.

\section{Reversibility of the monocrotaline pulmonary hypertension rat model}

\section{To the Editor:}

Pulmonary hypertension $(\mathrm{PH})$ is a disease characterised by progressive remodelling of the pulmonary vasculature eventually leading to right heart failure. Various animal models have been used to mimic the disease, involving pigs, dogs, rats and mice [1]. The most commonly used model is the monocrotaline (MCT) rat model. In this model MCT is injected subcutaneously and becomes metabolically activated, as a pyrrolizidine alkaloid, by hepatic cytochrome P450 3A [2,3]. The active MCT pyrrole is pneumotoxic and damages the pulmonary artery endothelial cells (PAECs), which leads to a disturbed barrier function [4]. Other features of MCT-induced pulmonary vascular remodelling are arterial medial hyperplasia of axial arteries, interstitial oedema, adventitial inflammation, haemorrhage and, eventually, fibrosis $[1,2,5,6]$. As a result, pulmonary vascular resistance (PVR) increases and the right ventricle compensates by hypertrophy and eventually fails $[7,8]$. 
Besides the MCT PH rat model, chronic hypoxia with or without Sugen 5416 and pulmonary artery banding are used to study experimental $\mathrm{PH}$ [1]. The $\mathrm{PH}$ animal model of choice is mostly dependent on the research question that needs to be answered. Ideally, an animal model would recapitulate the progressive and irreversible pulmonary vascular remodelling, which is the hallmark of human $\mathrm{PH}[1,4,9]$. However, none of the animal models fulfil this criterion. Concerns have been raised about the MCT rat model since many therapies were successful in MCT rats but not in humans with PH [4].

We, therefore, investigated the long-term progression and reversibility of MCT-induced $\mathrm{PH}$ in rats over 12 weeks, using a dose of $40 \mathrm{mg} \cdot \mathrm{kg}^{-1}$ in a randomised placebo-controlled study design. Since it is known that a high dose of MCT ( 60 or $80 \mathrm{mg} \cdot \mathrm{kg}^{-1}$ ) is fatal within 3-6 weeks, the only possible way to study the long-term effects of MCT was to use a lower dose $[7,8,10,11]$. Alterations in the lungs and heart were measured 4, 8, and 12 weeks after administration of MCT or saline.

We randomly assigned 22 male Wistar rats (Harlan Laboratories, Horst, The Netherlands) to a subcutaneous injection of either $40 \mathrm{mg} \cdot \mathrm{kg}^{-1} \mathrm{MCT}$ or saline when their body weight was $175-200 \mathrm{~g}$. Rats were sacrificed at either 4 weeks $(n=3$ control, $n=5$ MCT), 8 weeks $(n=3$ control, $n=4$ MCT), or 12 weeks $(\mathrm{n}=3$ control, $\mathrm{n}=4 \mathrm{MCT})$. Echocardiography was performed 3 weeks after MCT injection, to determine baseline haemodynamics, and on the day of sacrifice. Before sacrifice, all animals underwent a right heart catheterisation to construct right ventricle pressure-volume loops. Internal organs were harvested for histology. All methods have been described in detail previously [12]. Data are presented as mean \pm SD. The study was approved by the local animal ethics committee.

At baseline echocardiography, 3 weeks after MCT injection, all MCT rats had a higher PVR index compared with controls (mean of the three MCT groups: $4.33 \pm 2.58 \mathrm{mmHg} \cdot \mathrm{mL}^{-1} \cdot \mathrm{min}^{-1} \cdot \mathrm{mg}^{-1}$ versus controls: $\left.0.50 \pm 0.13 \mathrm{mmHg} \cdot \mathrm{mL}^{-1} \cdot \mathrm{min}^{-1} \cdot \mathrm{mg}^{-1} ; \quad \mathrm{p}<0.001\right)$ with decreased cardiac index $(0.14 \pm 0.06$ versus $\left.0.29 \pm 0.04 \mathrm{~mL} \cdot \mathrm{min}^{-1} \cdot \mathrm{g}^{-1} ; \mathrm{p}<0.001\right)$ and lower tricuspid annular plane systolic excursion (TAPSE) $(2.3 \pm 0.5$ versus $3.6 \pm 0.3 \mathrm{~mm} ; \mathrm{p}<0.001)$. Body weight was significantly lower in the MCT rats sacrificed at 4 weeks $(311 \pm 21 \mathrm{~g})$ compared with controls $(354 \pm 6 \mathrm{~g} ; \mathrm{p}<0.05)$. After 8 and 12 weeks body mass of the MCT rats $(405 \pm 27$ and $455 \pm 27 \mathrm{~g}$, respectively) was similar to age-matched controls (408 \pm 36 and $496 \pm 46$ g, respectively).

We observed a significantly higher PVR index in the MCT rats sacrificed at 4 weeks compared with controls (fig. 1a) with an increased right ventricle systolic pressure $(57.8 \pm 10.3$ versus $15.6 \pm 2.3 \mathrm{mmHg} ; \mathrm{p}<0.05)$. Although stroke volume and heart rate were decreased, cardiac index was relatively preserved (fig. 1b-d). However, cardiac index was negatively correlated to estimated right ventricle systolic pressure in all MCT rats $(r=-0.65 ; p=0.02$, fig. 1e) but not in control rats $(r=0.30 ; p=0.46$, data not shown $)$. Diminished right ventricle function compared with controls was seen by means of lower TAPSE $(2.0 \pm 0.6$ versus $3.7 \pm 0.3 \mathrm{~mm} ; \mathrm{p}<0.05)$, a trend to increased right ventricle wall thickness $(1.4 \pm 0.2$ versus $1.0 \pm 0.1 \mathrm{~mm}$; $\mathrm{p}=0.07)$ and increased right ventricle end-diastolic diameter $(6.2 \pm 1.3$ versus $3.5 \pm 0.5 \mathrm{~mm} ; \mathrm{p}<0.05)$. In line with these findings, invasive haemodynamic measurements demonstrated high right ventricle afterload $(\mathrm{Ea})$, increased right ventricle diastolic stiffness (Eed) and increased right ventricle systolic elastance (Ees, a measure of contractility) in MCT rats sacrificed at 4 weeks compared with age-matched controls (fig. $1 \mathrm{f}-\mathrm{h}$ ). Because Ea and Ees are increased to the same extent, ventriculo-arterial coupling, represented by Ees/Ea ratio, is preserved in all animals (fig. 1i). Interestingly, all aforementioned parameters are normalised at 8 and 12 weeks after MCT injection (fig. 1a-i).

Signs of right ventricle adaptation to high afterload after 4 weeks of MCT were also found at autopsy, since heart weight was increased compared with controls $(1.54 \pm 0.02$ versus $1.27 \pm 0.08 \mathrm{~g} ; \mathrm{p}<0.05)$. This was mainly due to an increase in right ventricle weight indicated by the high right ventricle/left ventricle+septal weight ratio $(0.63 \pm 0.11$ versus $0.28 \pm 0.06$ in controls; $\mathrm{p}<0.05)$. Lung weight was greater in MCT rats sacrificed at 4 weeks $(1.73 \pm 0.06$ versus $1.36 \pm 0.19$ g; $\mathrm{p}<0.05)$, but liver weight was reduced compared with controls $(11.8 \pm 0.4$ versus $14.8 \pm 1.1 \mathrm{~g} ; \mathrm{p}<0.05)$. In MCT rats sacrificed at 8 and 12 weeks, the right ventricle/left ventricle+septal weight ratio was decreased compared with MCT rats sacrificed at 4 weeks, but not completely normalised ( 8 weeks: $0.37 \pm 0.03$ and 12 weeks: $0.40 \pm 0.07$, both $\mathrm{p}<0.01$ versus 4 weeks MCT). In addition, lung wet weight reduced to $1.74 \pm 0.17 \mathrm{~g}$ in MCT rats sacrificed at 8 weeks and $1.59 \pm 0.10 \mathrm{~g}$ in MCT rats sacrificed at 12 weeks. Liver weight increased to control values in MCT rats sacrificed at 8 and 12 weeks ( $14.0 \pm 0.67$ and $15.2 \pm 1.4 \mathrm{~g}$, respectively).

Lung histology showed increased media muscularisation in the smallest arterioles $(<40 \mu \mathrm{m})$ after 4 weeks of MCT $(32 \pm 4 \% ; \mathrm{p}<0.01$ versus controls) which returned to control values $(24 \pm 1 \%)$ after 8 weeks $(25 \pm 6 \%)$ and 12 weeks after MCT administration $(21 \pm 7 \% ; \mathrm{p}<0.05$ versus 4 weeks MCT) (fig. $1 j-1)$. Right ventricle cardiomyocyte cross-sectional area was considerably increased in the MCT rats sacrificed at 4 weeks $\left(388 \pm 91 \mu \mathrm{m}^{2}\right)$ compared with controls $\left(258 \pm 44 \mu \mathrm{m}^{2} ; \mathrm{p}<0.001\right)$ and remained at that level at 8 

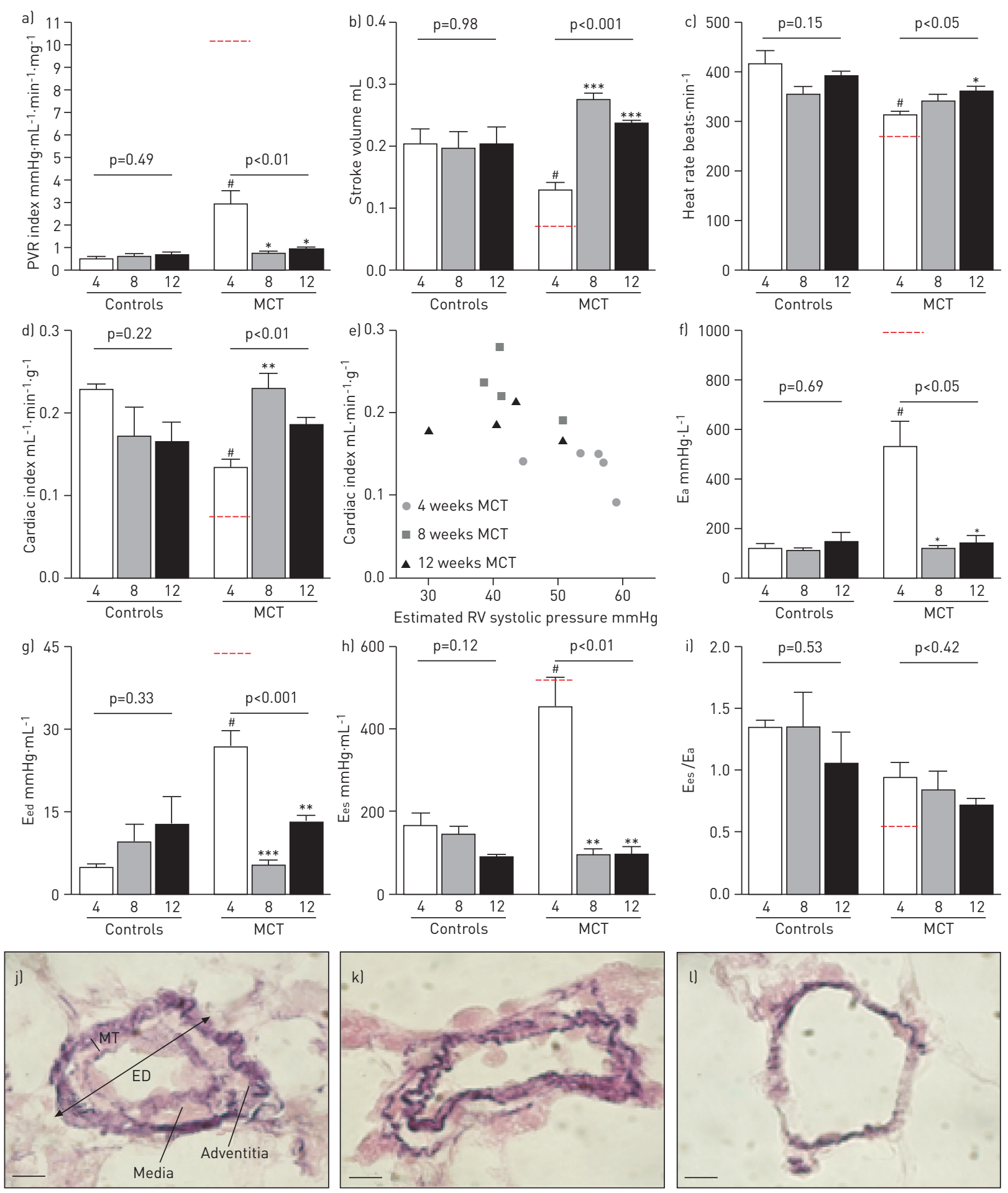

FIGURE 1 Echocardiographic, invasive haemodynamic and histology measurements. Data are presented as mean \pm sEM. a) Pulmonary vascular resistance (PVR), b) stroke volume, c) heart rate, d) cardiac index, e) cardiac index versus estimated right ventricular systolic pressure (eRVSP), f) arterial elastance (Ea) (right ventricle afterload), g) end diastolic elastance (Eed) (diastolic right ventricle stiffness), h) end systolic elastance (Ees) (right ventricle contractility), i) ventriculoarterial coupling of the right ventricle (Ees/Ea ratio). In a-i) the red dotted lines represent values at 4 weeks after injection with $60 \mathrm{mg} \cdot \mathrm{kg}^{-1} \mathrm{monocrotaline}(\mathrm{MCT})$, data from DE MAN et al. [12]. The three control and MCT-groups are compared with each other using one-way ANOVA with Bonferroni post hoc testing and pvalues are given on the graphs. ${ }^{*}: \mathrm{p}<0.05{ }^{* *}: \mathrm{p}<0.01{ }^{* * *}: \mathrm{p}<0.001$ compared with MCT rats sacrificed at 4 weeks. ${ }^{*}: \mathrm{p}<0.05$ for comparison of MCT rats with age-matched control values performed by Mann-Whitney testing. Histology of pulmonary arterioles from rats after j) 4, k) 8, and l) 12 weeks of MCT. Pulmonary arterioles were stained with the Elastica von Gieson method to visualise the tunica media, which is hypertrophied in animals sacrificed at 4 weeks. In addition, the adventitial layer is thickened compared with controls and MCT rats sacrificed at 8 and 12 weeks. Media thickness was measured as: $(2 \times$ media thickness(MT)/external diameter(ED) $) \times 100 \%$. 
and 12 weeks ( $344 \pm 76 \mu \mathrm{m}^{2}$ and $358 \pm 57 \mu \mathrm{m}^{2}$, respectively). Although right ventricle cardiomyocyte size was greater in MCT rats, the number of capillaries was similar in all MCT groups (mean $1.2 \pm 0.5$ capillaries per cardiomyocyte). Right ventricle fibrosis was similar at all time points in MCT animals and controls $(0.6 \pm 0.3$ versus $0.6 \pm 0.4 \%$ collagen; $p=0.88)$. In addition, right ventricle inflammation, expressed as the number of CD45 positive leukocyte cells per unit area was similar in all MCT animals (mean $25.8 \pm 15.4$ $\mathrm{CD}^{+} 5^{+}$nuclei $\cdot \mathrm{mm}^{-2}$ ) and similar to controls (mean $19.5 \pm 15.8 \mathrm{CD} 5^{+}$nuclei $\cdot \mathrm{mm}^{-2} ; \mathrm{p}=0.17$ ), indicative of a compensated rather than a failing right ventricle.

The MCT model is considered, by some, to be a toxic model and it has been suggested that MCT rats die from hepatic veno-occlusive disease with liver failure instead of right ventricle failure [13]. In the current study, liver weight was lower in MCT rats sacrificed at 4 weeks compared with controls. However, right ventricle systolic pressure and PVR are largely increased in these rats and increased pulmonary arteriolar muscularisation is found, which cannot be explained by liver damage alone.

To conclude, we demonstrated that $40 \mathrm{mg} \cdot \mathrm{kg}^{-1} \mathrm{MCT}$ induces acute muscularisation of the smallest pulmonary arterioles, together with high PVR and right ventricle hypertrophy at 4 weeks after MCT administration. However, at 8 and 12 weeks after MCT administration, the pulmonary arteriolar abnormalities were restored accompanied by normalisation of right ventricular function, although cardiomyocyte hypertrophy was maintained. This shows that MCT induced PH is reversible after 4 weeks and does not resemble the progressive nature of human PH. Therefore, this model is not suitable for therapeutic studies after 4 weeks of a low dose of MCT.

0 @ERSpublications

Pulmonary vascular remodelling and right ventricular adaptation in rats treated with monocrotaline $40 \mathrm{mg} \cdot \mathrm{kg}^{-1}$ is completely restored after 8 and 12 weeks http://ow.ly/luztH

Gerrina Ruiter $^{1,2}$, Frances S. de Man ${ }^{1}$, Ingrid Schalij ${ }^{1,2}$, Shellice Sairras ${ }^{1}$, Katrien Grünberg ${ }^{3}$, Nico Westerhof ${ }^{2}$, Willem J. van der Laarse ${ }^{2}$ and Anton Vonk-Noordegraaf ${ }^{1}$

${ }^{1}$ Dept of Pulmonology, Institute for Cardiovascular Research, VU University Medical Center, Amsterdam, ${ }^{2}$ Dept of Physiology, Institute for Cardiovascular Research, VU University Medical Center, Amsterdam, and ${ }^{3}$ Dept of Pathology, Institute for Cardiovascular Research, VU University Medical Center, Amsterdam, The Netherlands.

Correspondence: A. Vonk-Noordegraaf, Dept of Pulmonology, Institute for Cardiovascular Research, VU University Medical Center, De Boelelaan 1117, 1081 HV Amsterdam, The Netherlands. E-mail: a.vonk@vumc.nl

Received: Jan 212013 | Accepted after revision: March 242013

Conflict of Interest: Disclosures can be found alongside the online version of this article at www.erj.ersjournals.com

\section{References}

1 Stenmark KR, Meyrick B, Galie N, et al. Animal models of pulmonary arterial hypertension: the hope for etiological discovery and pharmacological cure. Am J Physiol Lung Cell Mol Physiol 2009; 297: L1013-L1032.

2 Huxtable RJ. Activation and pulmonary toxicity of pyrrolizidine alkaloids. Pharmacol Ther 1990; 47: 371-389.

3 Campian ME, Hardziyenka M, Michel MC, et al. How valid are animal models to evaluate treatments for pulmonary hypertension? Naunyn Schmiedebergs Arch Pharmacol 2006; 373: 391-400.

4 Gomez-Arroyo JG, Farkas L, Alhussaini AA, et al. The monocrotaline model of pulmonary hypertension in perspective. Am J Physiol Lung Cell Mol Physiol 2012; 302: L363-L369.

5 Lee YS, Byun J, Kim JA, et al. Monocrotaline-induced pulmonary hypertension correlates with upregulation of connective tissue growth factor expression in the lung. Exp Mol Med 2005; 37: 27-35.

Firth AL, Mandel J, Yuan JX. Idiopathic pulmonary arterial hypertension. Dis Model Mech 2010; 3: $268-273$.

Hessel MH, Steendijk P, den Adel B, et al. Characterization of right ventricular function after monocrotalineinduced pulmonary hypertension in the intact rat. Am J Physiol Heart Circ Physiol 2006; 291: H2424-H2430.

8 Handoko ML, de Man FS, Happé CM, et al. Opposite effects of training in rats with stable and progressive pulmonary hypertension. Circulation 2009; 120: 42-49.

9 Ryan J, Bloch K, Archer SL. Rodent models of pulmonary hypertension: harmonisation with the world health organisation's categorisation of human PH. Int J Clin Pract Suppl 2011; 172: 15-34.

10 Jones JE, Mendes L, Rudd MA, et al. Serial noninvasive assessment of progressive pulmonary hypertension in a rat model. Am J Physiol Heart Circ Physiol 2002; 283: H364-H371.

11 Hardziyenka M, Campian ME, de Bruin-Bon HA, et al. Sequence of echocardiographic changes during development of right ventricular failure in rat. J Am Soc Echocardiogr 2006; 19: 1272-1279.

12 de Man FS, Handoko ML, van Ballegoij JJ, et al. Bisoprolol delays progression towards right heart failure in experimental pulmonary hypertension. Circ Heart Fail 2012; 5: 97-105.

13 Roth RA, Dotzlaf LA, Baranyi B, et al. Effect of monocrotaline ingestion on liver, kidney, and lung of rats. Toxicol Appl Pharmacol 1981; 60: 193-203. 